\title{
Interspecific variation in avian thermoregulatory patterns and heat dissipation behaviours in a subtropical desert
}

Michelle Thompson ${ }^{1}$

Susan Cunningham ${ }^{2}$

Andrew E. McKechnie ${ }^{1,3}$

${ }^{1}$ DST-NRF Centre of Excellence at the Percy FitzPatrick Institute, Department of Zoology and Entomology, University of Pretoria, Pretoria, South Africa

${ }^{2}$ DST-NRF Centre of Excellence at the Percy FitzPatrick Institute, University of Cape Town, Cape Town, South Africa

${ }^{3}$ South African Research Chair in Conservation Physiology, National Zoological Gardens of South Africa, P.O. Box 754, Pretoria 0001, South Africa

Corresponding author: AE McKechnie, email: aemckechnie@zoology.up.ac.za

\section{Highlights}

- Avian setpoint body temperatures were higher than expected.

- Body temperature responses to increasing air temperature varied greatly among species.

- Most species avoided prolonged periods of hyperthermia.

- Seeking shade and reducing activity are important for themoregulation in many species.

- Linking behaviour to physiological thermoregulation requires species-specific data. 


\begin{abstract}
Deserts are physiologically challenging environments for birds, with scarce, unpredictable water resources combined with air temperatures ( $\left.T_{\text {air }}\right)$ regularly exceeding avian body temperature $\left(T_{\mathrm{b}}\right)$. For arid-zone birds, mismatches between water supply and demand are a constant threat, yet interspecific variation in trade-offs between hyperthermia avoidance and dehydration avoidance remain poorly understood, particularly for free-ranging individuals. We examined behavioural and physiological responses to high $T_{\text {air }}$ in nine species representing three orders that vary substantially in their heat dissipation thresholds, specifically pant 50 , the $T_{\text {air }}$ at which panting behaviour is present in $50 \%$ of observations. Birds housed during mid-summer in large free-flight aviaries in the Kalahari Desert each received a surgically-implanted $T_{\mathrm{b}}$ logger, and we quantified shade-seeking, activity and panting behaviours to examine relationships between species-specific pant $t_{50}$ and $T_{\mathrm{b}}$ regulation. Overall, species setpoint $T_{\mathrm{b}}$ values were higher (range: $41.4 \pm 0.5^{\circ} \mathrm{C}$ to $43.1 \pm 0.4^{\circ} \mathrm{C}$ ) than expected with maximum $T_{\mathrm{b}}$ values of $43.4-45.5^{\circ} \mathrm{C}$. Interspecific variation in $T_{\mathrm{b}}$ patterns at high $T_{\text {air }}$ was substantial, with $T_{\mathrm{b}}$ increasing with $T_{\text {air }}$ in most species, whereas in others no pattern or a negative relationship between $T_{\mathrm{b}}$ and $T_{\text {air }}$ was evident. Most species avoided prolonged hyperthermia, with reductions in activity and increased shade-seeking evidently adequate to manage heat load without resorting to hyperthermia in in several of our study species. Access to drinking water and food resources in captivity may have affected $T_{\mathrm{b}}$ patterns. Our data reveal that thermoregulation varies substantially among species, and suggest that free-ranging birds in hot, arid environments may maintain higher $T_{b}$ than currently thought.
\end{abstract}

\title{
Keywords: hyperthermia, thermal physiology, trade-off, Passeriformes, Columbiformes, Coliiformes.
}

\section{Introduction}

In hot, arid environments daily air temperatures can routinely exceed avian normothermic body temperatures. One major physiological challenge facing desert birds, therefore, is the maintenance of stable core body temperature $\left(T_{b}\right)$ and avoidance of lethal hyperthermia (Dawson \& Bartholomew 1968, Prinzinger et al. 1991, Tieleman \& Williams 1999, Møller 2010). Birds respond to increases in $T_{b}$ via physiological and behavioural adjustments that return $T_{\mathrm{b}}$ to a normothermic range, which often involve costs related to increased water and/or energy demands (Dawson \& Bartholomew 1968). During hot weather, when $T_{\text {air }}$ approaches or exceeds the normothermic setpoint $T_{\mathrm{b}}\left(T_{\mathrm{bset}}\right)$, passive heat loss ceases (Wolf 2000, Nilsson et al. 2016) and birds need to actively dissipate heat via evaporation to avoid $T_{\mathrm{b}}$ reaching lethal limits $\left(\sim 46-48^{\circ} \mathrm{C}\right.$; Dawson \& Schmidt-Nielsen 1964, Tieleman \& Williams 
1999, Whitfield et al. 2014). Birds increase rates of evaporative heat loss via a combination of respiratory and cutaneous evaporative heat loss (REWL and CEWL, respectively). The contribution of these two avenues to evaporative cooling varies among taxa (Wolf \& Walsberg 1996, McKechnie et al. 2016). Elevated CEWL promotes heat loss without the metabolic heat production associated with the muscle contractions required for panting (REWL), and therefore appears to be the more efficient mechanism of evaporative heat dissipation (Marder \& Arieli 1988, McKechnie \& Wolf 2004).

Irrespective of the pathways involved, high rates of evaporative cooling are problematic in desert environments where dehydration risk is high and surface water scarce (Dawson 1954, Bartholomew \& Cade 1956). For example, at very high $T_{\text {air }}$ small birds can lose $>5 \%$ of body mass per hour via evaporation (Wolf \& Walsberg 1996). To reduce water loss through evaporative cooling in hot environments, birds may show regulated, reversible increases in $T_{b}$ (facultative hyperthermia; reviewed by Tieleman \& Williams 1999). However, the potential benefits of hyperthermia also vary with body mass and among avian taxa (Tieleman \& Williams 1999, Whitfield et al. 2015, McKechnie et al. 2016) and even among populations within species (Smit et al. 2013). For instance, a desert population of White-browed SparrowWeavers (Plocepasser mahali) maintained higher $T_{\text {bset }}$ than individuals from milder semidesert sites, favouring a reduction in the use of hyperthermia (Smit et al. 2013).

Birds use behavioural adjustments such as reducing activity and increasing shadeseeking behaviour to reduce physiological costs of thermoregulation at high $T_{\text {air }}$ (Calder \& King 1974, Wolf 2000, Dawson 1982, Wolf 2000). However, the conflict between actively foraging to maintain energy and water budgets, and hyperthermia avoidance by reducing activity and seeking shade can be expensive in terms of lost opportunity costs (Cunningham et al. 2013, 2015). Additionally, high $T_{\text {air }}$ can reduce overall fitness, as the aforementioned 
behaviours coupled with increases in heat dissipation behaviour (HDB, such as panting and wing-drooping) reduce foraging efficiency, causing short-term losses of body condition (Du Plessis et al. 2012, van de Ven 2017) and reduced parental care (Cunningham et al 2013, van de Ven 2017). Furthermore, there is considerable interspecific variation in the temperature dependence of HDB as well as activity and shade-seeking behaviours (Smit et al. 2016). The latter authors showed that the $T_{\text {air }}$ associated with $50 \%$ of a population panting or wing-drooping varies by $>21^{\circ} \mathrm{C}$ among species in the Kalahari. Such interspecific differences in the $T_{\text {air }}$ associated with the onset of HDB may provide a basis for using HDB thresholds to assess species vulnerability to high temperatures in hot environments, which consequently could be important for modelling avian responses to climate change (Smit et al. 2016). However, it is first necessary to establish whether functional links exist between interand intraspecific variation in HDB and $T_{\mathrm{b}}$ regulation (Smit et al. 2016).

Most data on avian thermoregulation at high $T_{\text {air }}$ originate from laboratory studies in which $T_{\mathrm{b}}$ is measured concomitantly with metabolic rates and evaporative water loss (e.g., Smith et al. 2015, Whitfield et al. 2015; McKechnie et al. 2016). However, laboratory studies may not accurately reflect thermoregulation under natural conditions, as ambient conditions are controlled, and activity restricted (Smit et al. 2013). The few studies that have examined diurnal $T_{\mathrm{b}}$ patterns in free-ranging birds during hot weather typically focus on just one or two species (Smit et al. 2013, O'Connor et al. 2017). These studies confirm that $T_{\mathrm{b}}$ patterns can differ substantially between free-ranging individuals and individuals held in respirometry chambers (O'Connor et al. 2017). Yet, despite the importance of thermoregulation and associated trade-offs in the ecology of desert birds, very little is known about interspecific differences in thermoregulatory patterns in free-ranging birds (Smit et al. 2013) or how these relate to species traits, including variation in the temperature-dependence of HDB. 
Recent years have seen an increasing interest in the notion that thermal performance of endotherms represents a continuum from thermal specialisation to generalisation, akin to that found in ectotherms (Angilletta et al. 2010, Boyles et al 2011a). This view posits that thermoregulation is co-adapted with thermal sensitivity of performance, such that trade-offs occur whereby some species maintain high performance over only a narrow $T_{\mathrm{b}}$ range, responding strongly to changes in $T_{b}$ (thermal specialists) whereas others tolerate a wider range of $T_{\mathrm{b}}$ but at lower performance levels and respond less to $T_{\mathrm{b}}$ changes (thermal generalists; Angilletta et al. 2010, Boyles et al. 2011a). Different environmental pressures likely alter the benefits of being either a thermal specialist or generalist. Yet, little is known about how much variation there is in the thermal performance breadth of specialists and generalist thermoregulators in specific environments, or whether species can shift from being a thermal specialist to a thermal generalist when heat stressed.

Here, we hypothesised that interspecific variation in HDB is functionally linked to body temperature regulation. We tested this hypothesis by examining patterns of $T_{\mathrm{b}}$ and behaviour in nine species that differ widely in the temperature dependence of panting, focussing specifically on panting thresholds, i.e. the $T_{\text {air }}$ at which panting behaviour is present in $50 \%$ of observations (pant50). Thus, we selected our nine study species on the basis of pant50; which varied by $>10^{\circ} \mathrm{C}$ with a range from $34.5-45.5^{\circ} \mathrm{C}$ (Smit et al. 2016). We, 1) quantified interspecific variation in $\left.T_{\mathrm{bset}}, 2\right)$ tested the prediction that $T_{\mathrm{b}}$ patterns correspond with pant50 in terms of how $T_{\mathrm{b}}$ responds to increasing $T_{\text {air, }}$ and 3) quantified hyperthermia use/avoidance across these species. 4.) We also tested the prediction that pant50 is related to activity patterns and shade-seeking behaviours at high $T_{\text {air. }}$ Due to the onset of active evaporative cooling when $T_{\text {air }}$ approaches normothermic $T_{b}$, we expected pant5o to be correlated with $T_{\text {bset, }}$ 
with species that pant at lower $T_{\text {air }}$ defending lower $T_{\text {bset }}$ and showing a lower degree of heterothermy.

\section{Methods \& Materials}

\subsection{Study animals and housing}

Table 1: Kalahari desert bird species used to compare variation in body temperature parameters. Each species has a unique abbreviation (Abb.) used for referral in figures and text. Species belong to three orders, passeriformes (PASS), columbifomes (COLU) and Coliiformes (COLI). Summer seasons where species were sampled are indicated by Season (2014 refers to Austral summer: i.e. Nov 2013-March 2014 etc). Species are categorised according to dominant dietary guild; i.e. frugivores (FRU), insectivores (INS), granivores (GRA), omnivores (OMN) using diet information from Hockey et al. 2005. Sample sizes for physiological $\left(N_{T b}\right)$ and behavioural data $\left(N_{\text {behav }}\right)$ included.

\begin{tabular}{lllcccr}
\hline Abb. & Order & \multicolumn{1}{c}{ Species } & Season & Diet & $\boldsymbol{N}_{\text {Tb }}\left(\boldsymbol{N}_{\text {behav }}\right)$ & $\begin{array}{c}\text { Body } \\
\text { mass }\end{array}$ \\
\hline WBM & COLI & White-backed Mousebird (Colius colius) & 2016 & FRU & $5(10)$ & $34.5 \pm 1.7$ \\
CGS & PASS & Cape Glossy Starling (Lamprotornis nitens) & $2015(2016)$ & OMN & $8(16)$ & $74.5 \pm 7.1$ \\
REB & PASS & African Red-eyed Bulbul (Pycnonotus nigricans) & 2014 & FRU & $7(10)$ & $29.3 \pm 2.2$ \\
WBS & PASS & White-browed Sparrow Weaver (Plocepasser & 2015 & OMN & $6(10)$ & $35.8 \pm 2.6$ \\
& & mahali) & & & & $129.5 \pm$ \\
CTD & COLU & Cape Turtle-Dove (Streptopelia capicola) & $2015(2016)$ & GRA & $11(16)$ & 11.3 \\
LAD & COLU & Laughing Dove (Streptopelia senegalensis) & 2015 & GRA & $8(11)$ & $89.6 \pm 9.9$ \\
SOW & PASS & Sociable Weaver (Philetairus socius) & 2014 & OMN & $8(9)$ & $24.0 \pm 1.0$ \\
FCL & PASS & Fawn-coloured Lark (Calendulauda africanoides) & 2014 & OMN & $6(8)$ & $23.9 \pm 0.7$ \\
NAD & COLU & Namaqua Dove (Oena capensis) & $2015(2016)$ & GRA & $8(19)$ & $36.9 \pm 2.3$ \\
\hline
\end{tabular}

We examined thermoregulation in nine bird species resident in the southern Kalahari Desert, representing three orders (Passeriformes, Columbiformes and Coliiformes). These species have a $\sim 6$-fold range in body mass and represent a variety of foraging guilds (Table 1). Birds were caught using species-appropriate trapping methods including mist-netting, spring traps baited with mealworms and walk-in traps baited with seed. Individual morphometric data including body mass were recorded upon capture, and birds were assigned a unique colour ring combination for individual identification while in captivity. Each species was kept separately for a single two-month period during either of the austral summers of 2014-2016 in one of three large outdoor aviaries (each $3 \mathrm{~m}$ high $\times 3 \mathrm{~m}$ wide $\times 8 \mathrm{~m}$ long). The aviaries were 
erected at Murray Game Ranch $\left(26^{\circ} 59^{\prime} \mathrm{S}, 20^{\circ} 51^{\prime} \mathrm{E}\right)$, a private farm $\sim 12 \mathrm{~km}$ east of the town of Askham in the Northern Cape province of South Africa. Birds were habituated to the aviaries for at least six days before experimentation began. Within the aviaries, birds experienced natural daily ambient temperature cycles. Shade was provided by covering one-third of the aviary roof with sheets of corrugated steel. Perches were placed at various heights and positions inside the aviaries, and a comparable range of perching locations was available in each aviary. Birds were fed species-specific diets; columbids were fed a diet of wild birdseed, omnivorous passerines were also maintained on a diet of wild birdseed with daily supplements of mealworms and occasional supplements of freshly caught insects (predominantly lacewings and moths) trapped around domestic light sources in the evenings. Frugivorous species were fed seasonal fresh fruit mixed with ProNutro breakfast cereal (Bokomo, Pioneer Foods Groceries (Pty) Ltd, Tygervalley, Western Cape, South Africa) occasionally supplemented with mealworms. All birds received water ad libitum during the measurements reported here.

\subsection{Body and air temperature measurements}

Measurements of $T_{\mathrm{b}}$ for the two larger species, Laughing Dove (hereafter LAD) and Cape Turtle-Dove (hereafter CTD), were obtained using miniature temperature loggers (Thermochron iButton, model 1922L, Maxim Dallas Semiconductors, Sunnyvale, California, USA) programmed to record $T_{b}$ every five minutes. For the remaining seven species (African Red-eyed Bulbul, Cape Glossy Starling, Fawn-coloured Lark, Namaqua Dove, Sociable Weaver, White-browed Sparrow-Weaver, White-backed Mousebird hereafter REB, CGS, FCL, NAD, SOW, WBS and WBM, respectively), we used surgically implanted temperaturesensitive radio transmitters (model BD-2TH, Holohil Systems Ltd., Carp, Ontario, Canada). A 
data logging station consisting of a VHF radio receiver / data logger (Lotek SRX_400 receiver, Lotek Wireless Inc., Newmarket, Ontario, Canada) was set up outside the aviaries. The logging station included a multiplexor to accommodate three Yagi antennae (one per aviary) with the receiver continuously cycling through transmitter frequencies in such a way that the $T_{\mathrm{b}}$ of individuals was recorded at roughly four-minute intervals. Signal interference in the shaded areas of the aviaries was common and often interrupted the continuous recording of $T_{\mathrm{b}}$. Individuals with intermittent $T_{\mathrm{b}}$ traces were omitted from the $T_{\mathrm{b}}$ analyses but data from all individuals were included in the behavioural analyses. The mass of loggers and transmitters mass was $\leq 5 \%$ of body mass of all birds, excepting SOW and FCL where mass was $<7.5 \%$ of body mass. Loggers and transmitters were coated with surgical wax before being implanted intraperitoneally into the abdominal cavities of the birds under inhalation anaesthesia by a qualified veterinarian (Dr A Lategan, SAVC reg. no. D90-3031). To allow a full recovery the surgery took place at least a week before data collection. All loggers/transmitters were precalibrated over a temperature range of $0-45^{\circ} \mathrm{C}$ in a circulating water bath against a mercury-in-glass thermometer with NIST-traceable accuracy. Drift in radio transmitters required $T_{\mathrm{b}}$ traces to be corrected (see Data analysis section).

Air temperature, dew point, rainfall and other weather variables were recorded at fiveminute intervals using a portable weather station (Vantage Pro2, Davis Instruments, Haywood, California, USA) placed within $400 \mathrm{~m}$ of the aviaries. Air temperature inside the aviaries ( $\left.T_{\text {aviary }}\right)$ was also measured using temperature data loggers (TidbiT v2 temperature data logger UTBI-001, Onset Computer Corporation, Bourne, Massachusetts, USA) placed 2 $m$ above the ground at perch level, in the shade at the back of each aviary. Each TidbiT was suspended inside a hollow plastic PVC tube $(20 \mathrm{~cm}$ long $\times 5 \mathrm{~cm}$ diameter) with holes drilled into the sides for ventilation. TidbiTs were synched with the weather station and recorded 
$T_{\text {aviary }}$ every five min. TidbiTs were also precalibrated following the same procedure as $T_{b}$ devices.

\subsection{Behavioural observations}

Behavioural data were collected by an observer seated far enough from the aviary that bird behaviour was not influenced by the observer's presence. The distance varied according to observed vigilance and alarm thresholds of the different species but generally ranged between 5-10 $\mathrm{m}$ from the aviary. We made instantaneous behavioural observations (Altmann 1974) per individual between $07: 00-12: 00 \mathrm{~h}$ and 14:00-17:30 $\mathrm{h}$ daily. This was done by observing an individual for a short time period ( 20 seconds) and recording basic binomial data on panting behaviour (none $=0$, panting $=1$ ), shade-seeking ( sun $=0$, shade $=1$ ) and activity (inactive $=0$, active $=1$ ). During these periods, individuals were sampled between $2-5$ times depending on the ease of individual identification. Numbers of individuals per species included for behavioural data are generally higher than for $T_{b}$, reflecting the exclusion from the analyses of individuals with poor $T_{\mathrm{b}}$ traces.

\subsection{Data analysis}

All statistical analyses were conducted in the R environment (R Core Team 2016).

\subsubsection{Transmitter drift correction}

The Holohil temperature-sensitive radio transmitters used in this study have been previously shown to exhibit signal drift (Williams et al. 2009, Cunningham et al. 2017), and we encountered the same issue during the present study. To correct for drift, we examined $T_{b}$ traces to identify where transmitters began to drift (break point) by running segmented models using the package segmented (Muggeo 2008) in R and, following the procedure of 
Cunningham et al. (2017), corrected each individual $T_{b}$ trace. Transmitters that did not start drifting immediately typically had break points between 8-15 days after implantation. The magnitude of drift in all transmitters varied anywhere between $0.02-0.13^{\circ} \mathrm{C} /$ day.

\subsubsection{Model fitting and selection}

We fitted a global model including all terms that we hypothesised could have an effect on the response variable. The best model was selected by comparing AICc (Akaike's Information Criteria, adjusted for small samples) between all possible models nested within the global model using the dredge function in R package MuMIn (Barton 2010), and selecting the model with the lowest AICc score. All top models had $\Delta$ AICc $>2$ points lower than the next best models. For all analyses, we visually inspected residuals of global and final models to ensure model assumptions were met. Statistical significance of the effects of retained predictor variables was inferred if $95 \%$ confidence intervals (Cls) excluded zero.

\subsubsection{Body temperature analyses}

Due to the failure of a number of $T_{b}$ data loggers in the 2014-15 season, experiments for three species (number of failures: $N A D=7, C T D=6, C G S=10$ ) were repeated during the 2015-16 summer (Table 1). For these species, $T_{b}$ data from different years were pooled. Analyses focused on $T_{b}$ patterns across the whole day, hereafter 'diurnal' as well as looking at during the hottest period of the day (12:00-19:20), hereafter referred to as 'hot'. Diurnal (07:00-19:20) variation in $T_{\mathrm{b}}$ was analysed using a simple comparative metric, the Heterothermy Index $(\mathrm{HI})$, which quantifies the extent of heterothermy for each individual bird by examining variation in $T_{b}$ around the modal diurnal normothermic $T_{b}$ (Boyles et al. 2011b), and is calculated as: 


$$
H I=\sqrt{\frac{\sum(T \mathrm{bmod}-T \mathrm{bi})^{2}}{n-1}}
$$

where $T_{\mathrm{bmod}}$ is the modal normothermic $T_{\mathrm{b}}$ of an individual, $T_{\mathrm{bi}}$ is the $T_{\mathrm{b}}$ at time $\mathrm{i}$, and $n$ is the number of times $T_{\mathrm{b}}$ is sampled (Boyles et al. 2011b).

In all analyses, we included individual as a random effect to account for repeated measures per individual. Differences in $T_{\text {bmod }}$ and $\mathrm{HI}$ between species were modelled using linear mixed models (LMM) with fixed factors species and mass run with the package Ime4 (Bates et al. 2015). Body mass for each species was calculated as the mean mass of all study individuals. Tukey post-hoc tests using multcomp (Hothorn 2008) were used to identify significant differences between species and correlations between $T_{b m o d}$ and $\mathrm{HI}$ were tested using Pearson's product-moment correlation. Following Smit et al. (2013) Tbmod was determined by pooling all $T_{\mathrm{b}}$ recorded in the early morning (07:00-10:00), when birds were active but unlikely to be heat stressed.

For each species, we then modelled diurnal $T_{\mathrm{b}}$ and hot $T_{\mathrm{b}}$ as a function of $T_{\text {aviary, }}$ controlling for time of day (diurnal $T_{b}$ only) and body mass using LMM. Time of day (TOD) was divided into three periods, early: 07:00-10:00 when birds are active but not heat stressed, midday: 10:00-14:00, and afternoon: 14:00-19:20 where $T_{\text {aviary }}$ peaked. Tukey posthoc tests were used to examine differences in diurnal $T_{\mathrm{b}}, T_{\mathrm{bmod}}$ and $\mathrm{HI}$ with time of day (early: 07:00-10:00, midday: 10:00-14:00, afternoon: 14:00-19:20).

\subsubsection{Behavioural analyses}

Individual was included as a random factor in all behavioural analyses. For activity, panting and shade-seeking behaviour, $T_{\text {aviary }}$ was the only significant predictor present in top models. We used model predictions for each species to determine the $T_{\text {aviary }}$ at which panting behaviour was present in $50 \%$ of observations (pant50) following Smit et al. (2016). 
Additionally, following the same methodology, we also calculated the $T_{\text {aviary }}$ at which shadeseeking behaviour was present in $50 \%$ of observations (shade 50 ) and the $T_{\text {aviary }}$ at which species were active in $50 \%$ of observations (activity 50 ). Activity 50 models for CTD and REB did not converge. The removal of a single CTD individual for which no active observations were recorded resolved convergence issues for CTD. For REB, removal of any individual resolved convergence issues, with similar model outputs (all non-significant), regardless of the individual removed. The inability to identify which individual to remove ultimately meant REB model convergence issues remained unresolved. Further, Pearson's product-moment correlations were calculated to establish whether pant 50 correlated with $T_{\text {bset }}$ and mass.

\section{Results}

\subsection{Body temperature}

Diurnal $T_{\text {bmod }}$ varied among the nine species from $41.4 \pm 0.5^{\circ} \mathrm{C}$ in WBM to $43.1 \pm 0.4^{\circ} \mathrm{C}$ in REB (Table 2, Figure 1). Variation in diurnal $T_{\mathrm{b}}$, quantified as $\mathrm{HI}$ values, was similar among most species (Table 2). NAD had higher HI (i.e., Tb was more variable) in comparison 

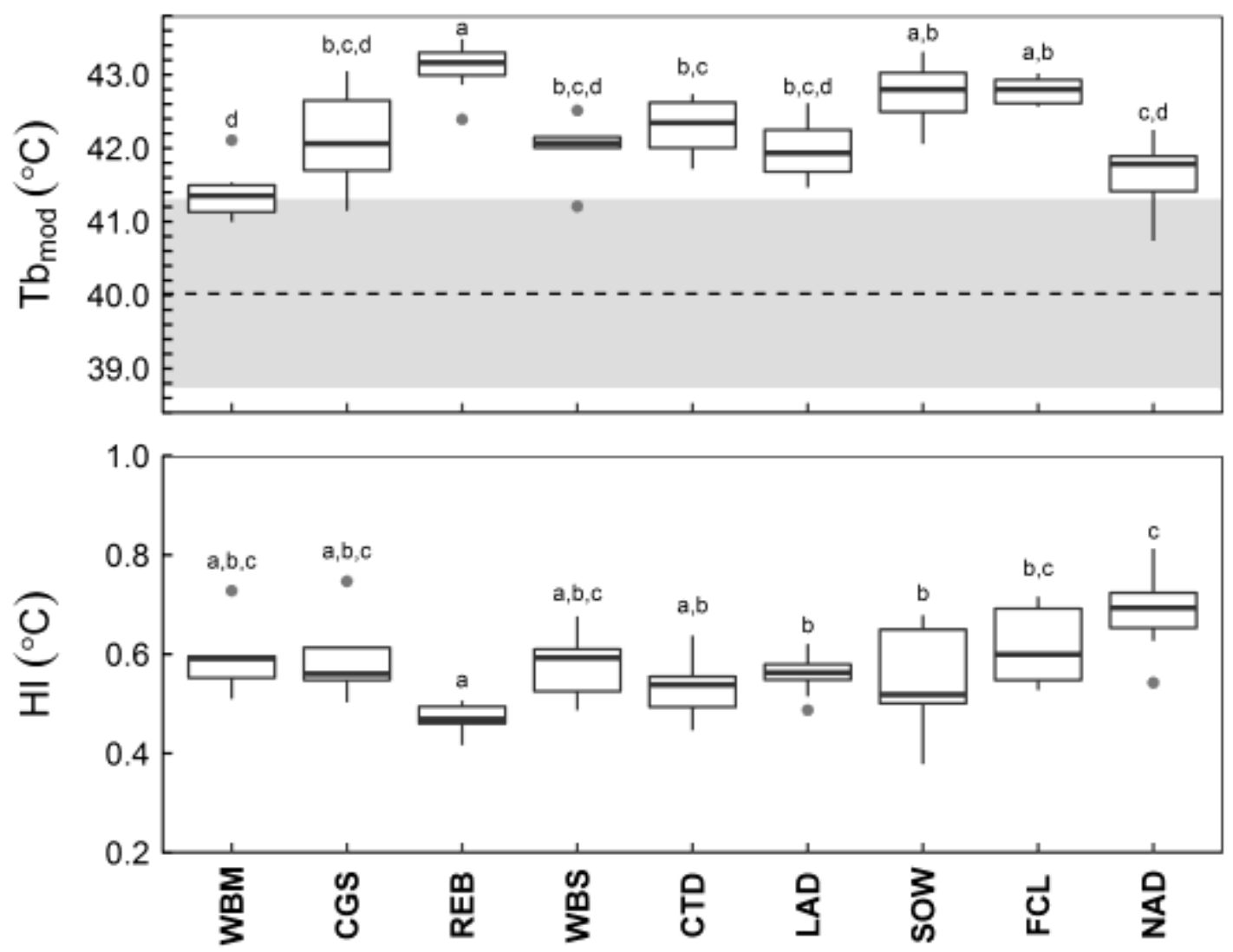

Figure 1: Interspecific differences in $T_{\text {bmod }}$ and heterothermy index $(\mathrm{HI})$ for nine species. Boxes represent means of individual $T_{\text {bmod }}$ and $\mathrm{HI}$. Species are arranged in order of heat dissipation thresholds (pant 50 ), from lowest (left) to highest (right; see Table 1). The dashed line in $T_{\text {bmod }}$ panel indicates the mean ( $\pm s d=$ grey ribbon) active phase $T_{\mathrm{b}}$ for 724 bird species taken from Prinzinger et al. (1991). Diurnal $7 \mathrm{bmod}$ generally fell above mean active phase $T_{b}$ for all birds. Differences between species are indicated by letters above boxes. If species share a letter, 95\% Cls include zero, and values do not differ. WBM = White-backed Mousebird, CGS = Cape Glossy Starling, REB = African Red-eyed Bulbul, WBS = White-browed Sparrow-Weaver, CTD = Cape Turtle-Dove, $\mathrm{LAD}=$ Laughing Dove, SOW $=$ Sociable Weaver, $\mathrm{FCL}=$ Fawn-coloured Lark, NAD = Namaqua Dove. to REB LAD, CTD and SOW. FCL also showed greater variation in $T_{b}$ than REB (Figure 1 ).

Among species $T_{\text {bmod }}$ and $\mathrm{HI}$ were not correlated, although REB had the highest $T_{\mathrm{bmod}}$ and the lowest HI, whereas NAD had low $T_{\text {bmod }}$ and the highest HI (Figure 1). 
Diurnal $T_{b}$ was predicted by $T_{\text {aviary }}$ in most species, but effect sizes were very small (Table 3; Figure 8, Appendix). In most species (CGS, WBS, CTD, SOW and NAD) $T_{\mathrm{b}}$

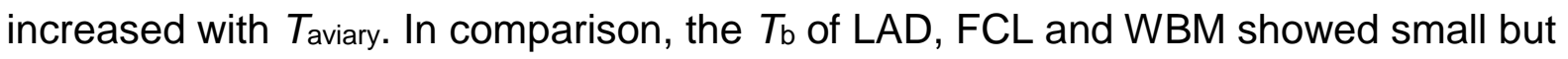
significant decreases with increases in $T_{\text {aviary }}$ (Table 3 ). The magnitude of the effect of $T_{\text {aviary }}$ on $T_{b}$ was influenced by the interaction of $T_{\text {aviary }}$ and mass in CGS and NAD, where smaller

Table 2: Body temperature $\left(T_{\mathrm{b}},{ }^{\circ} \mathrm{C}\right)$ summaries for species across a range of aviary air temperatures ( $T_{\text {aviary, }}$ $\left.{ }^{\circ} \mathrm{C}\right)$. Sample sizes differ for $T_{\mathrm{b}}$ data $\left(N_{T b}\right)$ and behavioural data $\left(N_{\text {behav }}\right)$ however, the number of days used $\left(N_{\text {days }}\right)$ is the same for both physiological and behavioural data collection. For the three species that were repeated, $N$ values are presented as Season 1 (Season 2) values. Data for $T_{\text {aviary }}$ and $T_{\mathrm{b}}$ variables for these species were pooled. Pant 50 was calculated using panting observations observed across the range of $T_{\text {aviary }}$. The most frequent $T_{\mathrm{b}}$ during the time of day when birds are active but not thermally stressed, i.e. using all $T_{\mathrm{b}}$ recorded during early morning (7:00-10:00) when $T_{\text {aviary }}$ is lower, represents $T_{\text {bmod. }} T_{\text {bmean }}$ was calculated using $T_{\mathrm{b}}$ recorded throughout diurnal period whilst $T_{\mathrm{bmax}}$ was the maximum $T_{\mathrm{b}}$ recorded for the species during the hottest period (12:00-19:20). Heterothermy index (HIdiurnal) expresses variation in $T_{\mathrm{b}}$ accounting for deviation from $T_{\text {bmod }}$ and time spent away from $T_{\text {bmod. }}$

\begin{tabular}{|c|c|c|c|c|c|c|c|c|}
\hline \multirow[t]{2}{*}{ pecies } & \multirow[t]{2}{*}{ pant50 } & \multirow[t]{2}{*}{$N_{T b}, N_{b e h a v}$} & \multirow[t]{2}{*}{$N_{\text {days }}$} & \multirow[t]{2}{*}{$T_{\text {aviary }}$ range } & \multicolumn{3}{|c|}{ Body temperature variables $\left({ }^{\circ} \mathrm{C}\right)$} & \multirow[b]{2}{*}{ Hldiurnal } \\
\hline & & & & & $T b_{\text {mod }}$ & $T \mathrm{~b}_{\text {mean }}$ & $7 b_{\max }$ & \\
\hline WBM & 36.3 & 6,10 & 7 & $16.0-41.8$ & $41.4 \pm 0.5$ & $41.1 \pm 0.7$ & 43.4 & $0.58 \pm 0.16$ \\
\hline CGS & 36.6 & $1(4), 11(10)$ & $4(9)$ & $14.6-44.3$ & $42.1 \pm 0.7$ & $42.0 \pm 0.7$ & 43.9 & $0.59 \pm 0.21$ \\
\hline REB & 37.4 & 7,10 & 12 & $17.6-40.5$ & $43.1 \pm 0.4$ & $43.0 \pm 0.5$ & 45.4 & $0.47 \pm 0.10$ \\
\hline WBS & 38.3 & 6,10 & 8 & $17.3-44.3$ & $42.0 \pm 0.4$ & $42.1 \pm 0.6$ & 44.6 & $0.59 \pm 0.25$ \\
\hline CTD & 39.1 & $5(6), 10(6)$ & $8(12)$ & $8.8-41.2$ & $42.4 \pm 0.4$ & $42.3 \pm 0.7$ & 44.7 & $0.54 \pm 0.12$ \\
\hline LAD & 43.8 & 8,11 & 12 & $10.5-40.8$ & $42.0 \pm 0.4$ & $42.0 \pm 0.6$ & 44.2 & $0.56 \pm 0.12$ \\
\hline sow & 44.7 & 8,9 & 13 & $16.1-40.5$ & $42.8 \pm 0.4$ & $42.8 \pm 0.6$ & 45.5 & $0.56 \pm 0.19$ \\
\hline $\mathrm{FCL}$ & 46.1 & 6,6 & 12 & $17.6-40.5$ & $42.8 \pm 0.2$ & $42.1 \pm 0.5$ & 44.7 & $0.61 \pm 0.16$ \\
\hline NAD & -- & $3(5), 3(5)$ & $8(7)$ & $12.8-41.8$ & $41.6 \pm 0.4$ & $41.9 \pm 0.8$ & 45.4 & $0.67 \pm 0.22$ \\
\hline
\end{tabular}


Table 3: Effect sizes, ([95\% lower - upper Cls], t-values) of predictor variables retained in the top model for $T_{\mathrm{b}}$ for each species. Models were fitted to data for the entire diurnal period (07:00-19:20) and for the hottest period of the day (12:00-19:20). Global models tested the effect of aviary temperature ( $\left.T_{\text {aviary }}\right)$, mass, time of day (TOD; only for diurnal models) and the interactions between $T_{\text {aviary }}{ }^{*}$ mass and $T_{\text {aviary }}{ }^{*} T O D$ on $T_{b}$. If factors were not present in the top model cells were left blank. Values in bold indicate that $95 \% \mathrm{Cls}$ do not include zero.

\begin{tabular}{|c|c|c|c|c|c|c|c|}
\hline Species & Model & $N$ & $T_{\text {aviary }}\left({ }^{\circ} \mathrm{C}\right)$ & Mass (g) & TOD & $T_{\text {aviary }}{ }^{\star}$ Mass & $T_{\text {aviary }}{ }^{\star}$ TOD \\
\hline \multirow[t]{2}{*}{ White-backed Mousebird } & diurnal & 6 & $\begin{array}{l}-0.01 \\
{[-0.02--0.00]} \\
t=2.29\end{array}$ & & + & & + \\
\hline & hot & 6 & $\begin{array}{l}0.72 \\
{[0.47-0.97]} \\
t=5.63\end{array}$ & $\begin{array}{l}0.79 \\
{[0.43-1.14]} \\
t=4.08\end{array}$ & & $\begin{array}{l}-0.02 \\
{[-0.03--0.01]} \\
t=-5.72\end{array}$ & \\
\hline \multirow[t]{2}{*}{ Cape Glossy Starling } & diurnal & 5 & $\begin{array}{l}0.16 \\
{[0.13-0.19]} \\
t=11.10\end{array}$ & $\begin{array}{l}0.04 \\
{[-0.04-0.13]} \\
t=0.99\end{array}$ & + & $\begin{array}{l}-0.00 \\
{[-0.00--0.00]} \\
t=-7.8\end{array}$ & \\
\hline & hot & 5 & $\begin{array}{l}0.05 \\
{[0.05-0.06]} \\
t=15.36\end{array}$ & & & & \\
\hline
\end{tabular}

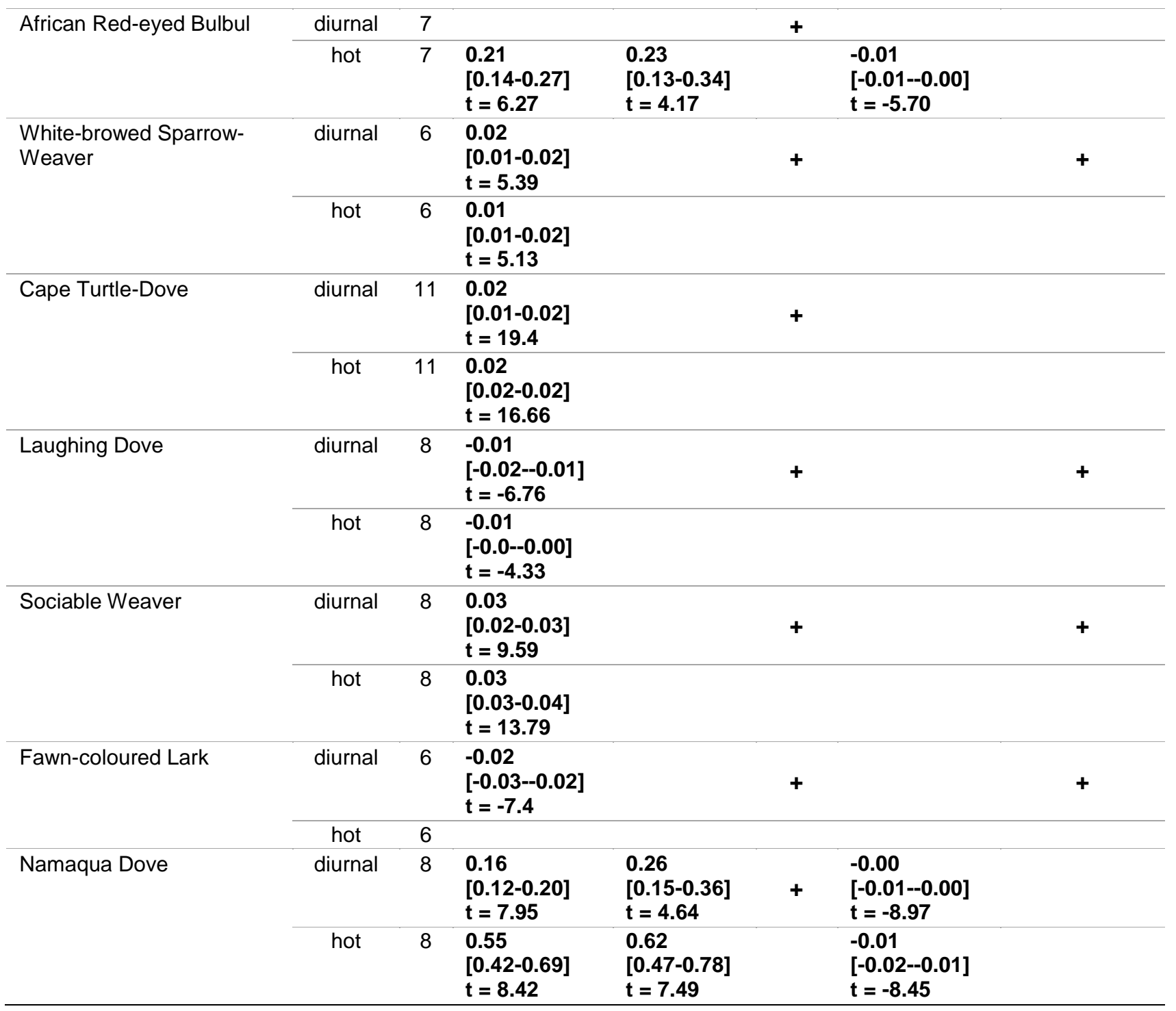


birds increased $T_{\mathrm{b}}$ more than larger birds as $T_{\text {aviary }}$ increased (Table 3 ). During the hottest part of the day (12:00-19:20), $T_{\text {aviary }}$ was the only significant predictor of $T_{\mathrm{b}}$ for CGS, WBS, SOW, CTD and LAD. No factors emerged as good predictors of $T_{\mathrm{b}}$ for FCL during the hottest portion of the day (Table 3). During the hottest part of the day all species increased $T_{b}$ with increasing $T_{\text {aviary, }}$ except LAD, in which $T_{\mathrm{b}}$ decreased with $T_{\text {aviary }}$; as with the diurnal analyses, the

Table 4: Differences in $T_{b}$ between three time of day (TOD) categories (early: 07:00-10:00, mid: 10:00-14:00, aft: 14:00-19:20). Mean $T_{\mathrm{b}} \pm \mathrm{sd}$ for the three TOD categories are included. Model outputs* are presented as effect sizes, [95\% lower - upper Cls], t-statistic. Values in bold indicate 95\% Cls that exclude zero.

\begin{tabular}{|c|c|c|c|c|c|c|}
\hline \multirow[t]{2}{*}{ Species } & \multicolumn{3}{|c|}{ mean $T_{b} \pm s d$} & \multicolumn{3}{|c|}{ Model output } \\
\hline & early & mid & aft & early - aft & mid - aft & mid - early \\
\hline White-backed Mousebird & $41.3 \pm 0.7$ & $41.2 \pm 0.6$ & $41.1 \pm 0.6$ & $\begin{array}{l}0.34 \\
{[0.27-0.41]} \\
t=10.76\end{array}$ & $\begin{array}{l}0.06 \\
{[0.02-0.10]} \\
t=3.09\end{array}$ & $\begin{array}{l}-0.28 \\
{[-0.33--0.23]} \\
t=-10.49\end{array}$ \\
\hline Cape Glossy Starling & $42.0 \pm 0.7$ & $42.1 \pm 0.7$ & $42.2 \pm 0.7$ & $\begin{array}{l}0.25 \\
{[0.2-0.31]} \\
t=10.82\end{array}$ & $\begin{array}{l}-0.05 \\
{[-0.1-0.01]} \\
t=-2.49\end{array}$ & $\begin{array}{l}-0.31 \\
{[-0.36--0.25]} \\
t=-13.00\end{array}$ \\
\hline African Red-eyed Bulbul & $43.0 \pm 0.6$ & $42.8 \pm 0.4$ & $43.0 \pm 0.4$ & $\begin{array}{l}-0.02 \\
{[-0.04-0.01]} \\
t=-1.40\end{array}$ & $\begin{array}{l}-0.20 \\
{[-0.27-0.21]} \\
t=-17.00\end{array}$ & $\begin{array}{l}-0.22 \\
{[-0.24--0.14]} \\
t=-14.50\end{array}$ \\
\hline $\begin{array}{l}\text { White-browed Sparrow- } \\
\text { Weaver }\end{array}$ & $42.2 \pm 0.7$ & $42.0 \pm 0.6$ & $42.3 \pm 0.5$ & $\begin{array}{l}-0.19 \\
{[-0.24--0.13]} \\
t=-7.56\end{array}$ & $\begin{array}{l}-0.33 \\
{[-0.38--0.28]} \\
t=-14.87\end{array}$ & $\begin{array}{l}-0.14 \\
{[-0.2--0.1]} \\
t=-6.06\end{array}$ \\
\hline Cape Turtle-Dove & $42.5 \pm 0.6$ & $42.1 \pm 0.6$ & $42.4 \pm 0.7$ & $\begin{array}{l}0.15 \\
{[0.12-0.19]} \\
t=11.28\end{array}$ & $\begin{array}{l}-0.36 \\
{[-0.39--0.34]} \\
t=-31.23\end{array}$ & $\begin{array}{l}-0.52 \\
{[-0.55-0.49]} \\
t=-37.94\end{array}$ \\
\hline Laughing Dove & $42.1 \pm 0.7$ & $41.7 \pm 0.6$ & $42.1 \pm 0.6$ & $\begin{array}{l}-0.13 \\
{[-0.17--0.9]} \\
t=-7.49\end{array}$ & $\begin{array}{l}-0.42 \\
{[-0.46--0.4]} \\
t=-29.85\end{array}$ & $\begin{array}{l}-0.3 \\
{[-0.34-0.26]} \\
t=-17.91\end{array}$ \\
\hline Sociable Weaver & $42.8 \pm 0.7$ & $42.5 \pm 0.6$ & $42.9 \pm 0.6$ & $\begin{array}{l}0.09 \\
{[0.04-0.15]} \\
t=3.86\end{array}$ & $\begin{array}{l}-0.31 \\
{[-0.35--0.28]} \\
t=-23.3\end{array}$ & $\begin{array}{l}-0.41 \\
{[-0.46--0.36]} \\
t=-19.75\end{array}$ \\
\hline Fawn-coloured Lark & $42.9 \pm 0.6$ & $42.2 \pm 0.5$ & $42.7 \pm 0.5$ & $\begin{array}{l}-0.32 \\
{[-0.38--0.27]} \\
t=-13.97\end{array}$ & $\begin{array}{l}-0.62 \\
{[-0.66--0.58]} \\
t=-39.41\end{array}$ & $\begin{array}{l}-0.3 \\
{[-0.35--0.25]} \\
t=-13.4\end{array}$ \\
\hline Namaqua Dove & $41.8 \pm 0.8$ & $41.6 \pm 0.6$ & $42.3 \pm 0.7$ & $\begin{array}{l}-0.68 \\
{[-0.73--0.62]} \\
t=-28.78\end{array}$ & $\begin{array}{l}-0.72 \\
{[-0.77--0.68]} \\
t=-39.1\end{array}$ & $\begin{array}{l}-0.04 \\
{[-0.09-0.01]} \\
t=-2.02\end{array}$ \\
\hline
\end{tabular}

* Derived from Tukey post-hoc test using $T_{\mathrm{b}} \sim \mathrm{TOD}+T_{\text {aviary }}$ 

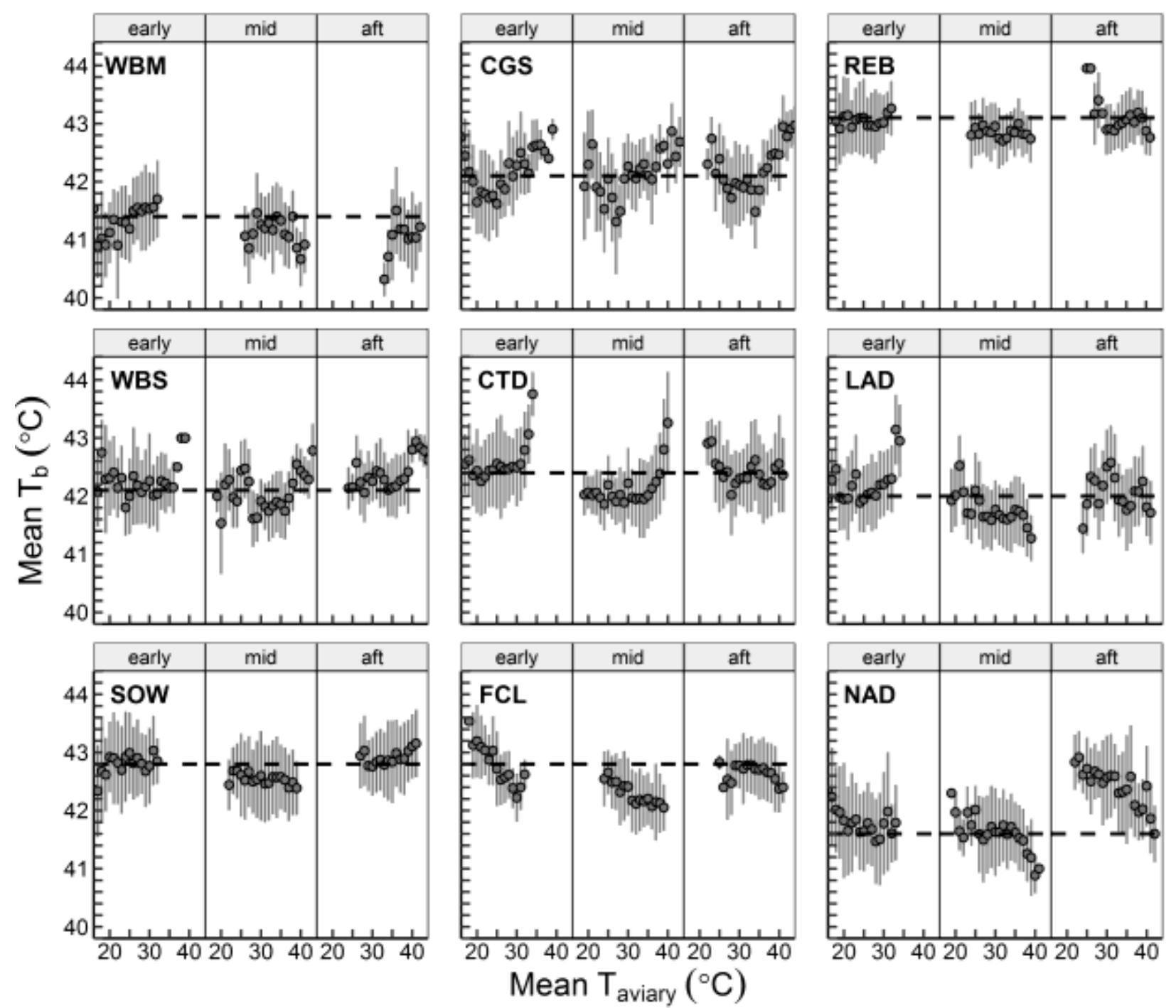

Figure 3: Changes in Mean $T_{\mathrm{b}}$ with increases in mean daily $T_{\text {aviary }}$ during 3 times of day (TOD) categories (early: 07:00-10:00, mid: 10:00-14:00, aft: 14:00-19:20). Mean $T_{\mathrm{b}}$ was calculated from all values binned in $1^{\circ} \mathrm{C}$ intervals of $T_{\text {aviary }}$. Error bars indicate standard deviation. WBM $=$ White-backed Mousebird, CGS = Cape Glossy Starling, REB = African Red-eyed Bulbul, WBS = White-browed Sparrow-Weaver, CTD = Cape Turtle-Dove, LAD = Laughing Dove, SOW = Sociable Weaver, FCL = Fawn-coloured Lark, NAD = Namaqua Dove. 
magnitude of effect sizes was small with changes of no more than $0.4^{\circ} \mathrm{C}$ per $10^{\circ} \mathrm{C}$ increase in $T_{\text {aviary }}$ (Table 3). For WBM and NAD mass and the interaction between mass and were also important predictors of $T_{\mathrm{b}}$ with smaller birds increasing $T_{\mathrm{b}}$ more than larger birds as $T_{\text {aviary }}$ increased. When this interaction term was removed, $T_{\text {aviary }}$ and mass were no longer significant predictors of $T_{\mathrm{b}}$. The highest $T_{\mathrm{b}}$ recorded during the hottest part of the day was in

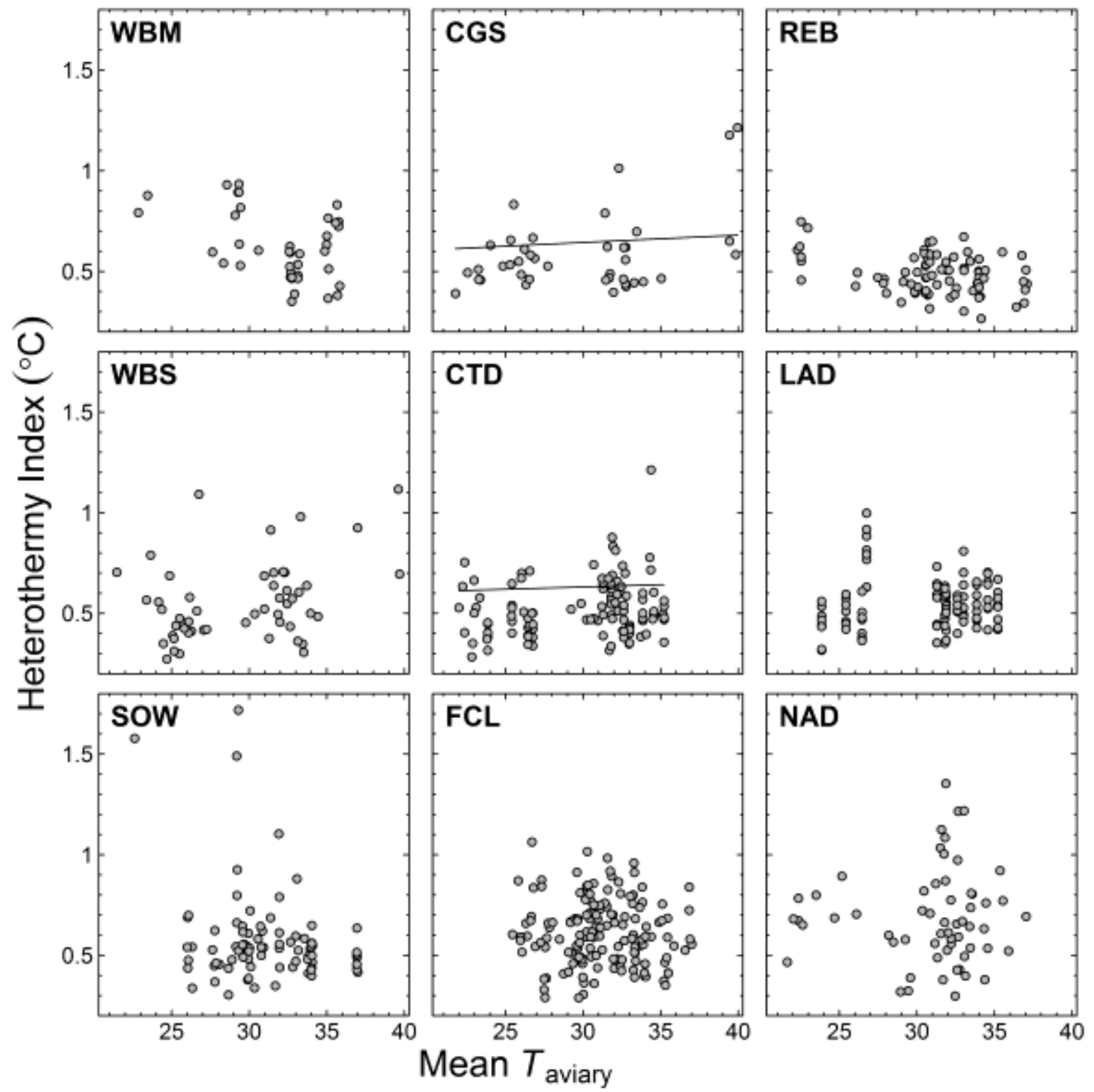

Figure 3: Variation in $T_{\mathrm{b}}$ reflected as heterothermy index $(\mathrm{HI})$ with increases in mean daily $T_{\text {aviary. }}$ CGS and CTD were the only species to increase $\mathrm{HI}$ with increases in mean $T_{\text {aviary. }}$. If the outlier in CTD is removed, the relationship is no longer significant. WBM $=$ White-backed Mousebird, CGS $=$ Cape Glossy, REB $=$ African Redeyed Bulbul, WBS $=$ White-browed Sparrow-Weaver, CTD $=$ Cape Turtle-Dove, LAD = Laughing Dove, SOW = Sociable Weaver, $\mathrm{FCL}=$ Fawn-coloured Lark, NAD = Namaqua Dove. 
NAD $\left(45.4^{\circ} \mathrm{C}\right)$ resulting in the greatest deviation of $T_{b}$ from $T_{b m o d}\left(T_{b m a x}-T_{b m o d}=3.8^{\circ} \mathrm{C}\right.$; Table 2). In all other species $T_{b \max }-T_{\mathrm{bmod}}<2.8^{\circ} \mathrm{C}$.

For all species time of day was a significant predictor of $T_{\mathrm{b}}$. However, diurnal patterns in $T_{\mathrm{b}}$ were species-specific and the magnitude of the difference in $T_{\mathrm{b}}$ between the three TOD categories was small (Table 4). Higher early morning $T_{b S}$ were maintained by WBM compared to the afternoon. During midday $T_{\mathrm{b}}$ decreased below early morning $T_{\mathrm{b}}$, with small but significant differences in $T_{\mathrm{b}}$ between midday and afternoon periods (Table 4 , Figure 2). A decrease in $T_{b}$ during midday compared to early mornings and the afternoons was observed in CGS, WBS, SOW, LAD, CTD and FCL (Table 4, Figure 2). During the afternoon, $T_{\mathrm{b}}$ in WBS, LAD and FCL was significantly higher than in the morning, whilst CGS, CTD and SOW had highest $T_{\mathrm{b}}$ early in the morning (Table 4). The $T_{\mathrm{b}}$ of Namaqua doves did not differ between early mornings and midday, but $T_{\mathrm{b}}$ was significantly higher ( $1^{\circ} \mathrm{C}$ higher than $T_{\mathrm{bmod}}$ ) during the afternoons (Table 4, Figure 2). There was an important interaction between $T_{\text {aviary }}$ and TOD in WBM, WBS, SOW, LAD and FCL (Figure 2). WBS and SOW showed increases in $T_{b}$ with increasing afternoon temperatures, whilst WBM, LAD and FCL decreased $T_{b}$ with increasing afternoon temperatures (Figure 2). For most species, $\mathrm{HI}$ was independent of $T_{\text {aviary }}$ (Figure 3). CGS and CTD showed a significant increase in $\mathrm{HI}$ with increasing $T_{\text {aviary }}$, however removal of the outlier for CTD resulted in the relationship no longer being significant in this species. In CGS, the magnitude of the effect was small with only a $\sim 0.2^{\circ} \mathrm{C}$ change in $\mathrm{HI}$ over a $10^{\circ} \mathrm{C}$ increase in mean $T_{\text {aviary }}$ (LMM: $0.02^{\circ} \mathrm{C},[0.01-0.03], \mathrm{t}=3.2$; Figure 3 )

\subsection{Behaviour}

Unexpectedly, activity was not correlated with $T_{\text {aviary }}$ in most species (Figure 4). WBM, CGS and SOW significantly decreased time spent active as $T_{\text {aviary }}$ increased, while LAD increased activity as $T_{\text {aviary }}$ increased. In contrast, panting behaviour increased with 
increasing $T_{\text {aviary }}$ for most species (Figure 5). Heat dissipation thresholds ranged from pant $50=36.3^{\circ} \mathrm{C}$ for WBM up to pant $50=46.1^{\circ} \mathrm{C}$ in FCL. NAD were only observed panting twice, at $T_{\text {aviary }}>38.8^{\circ} \mathrm{C}$. Thus, there were too few panting data to describe the relationship

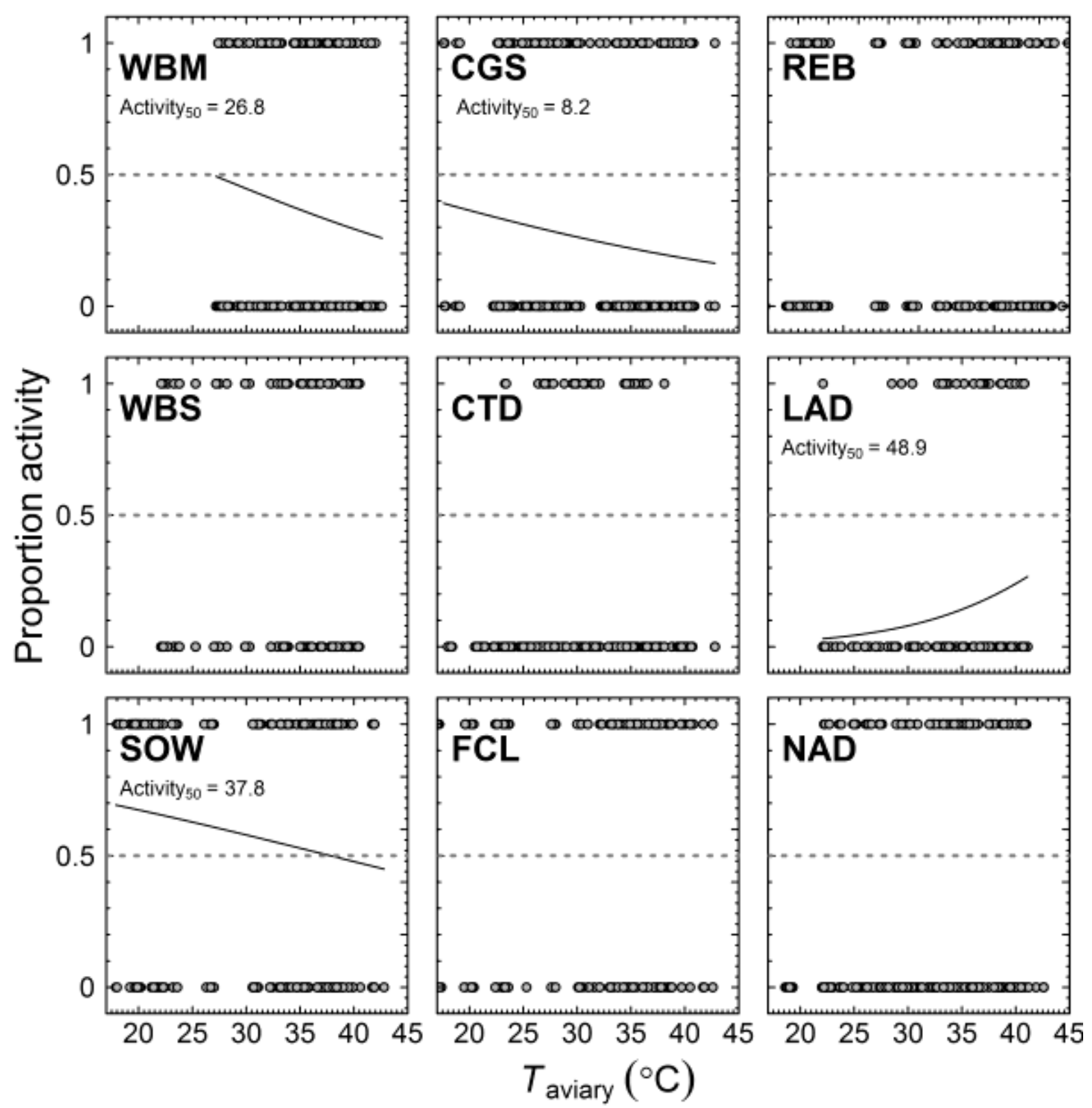

Figure 4: Proportion of time spent active as $T_{\text {aviary }}$ increases, where $1=$ active and $0=$ inactive. Activity 50 , the $T_{\text {aviary }}$ at which $50 \%$ of observed individuals are active, is displayed for species where the logistic regression models are significant. Models for REB did not converge. In most species activity is independent of $T_{\text {aviary }}$. Several species (WBM, CGS, SOW) decrease time spent active as $T_{\text {aviary }}$ increases while LAD increase activity as $T_{\text {aviary }}$ increases. WBM $=$ White-backed Mousebird, CGS = Cape Glossy, REB = African Red-eyed Bulbul, WBS = White-browed Sparrow-Weaver, CTD = Cape Turtle-Dove, LAD = Laughing Dove, SOW $=$ Sociable Weaver, $\mathrm{FCL}=$ Fawn-coloured Lark, NAD = Namaqua Dove. 

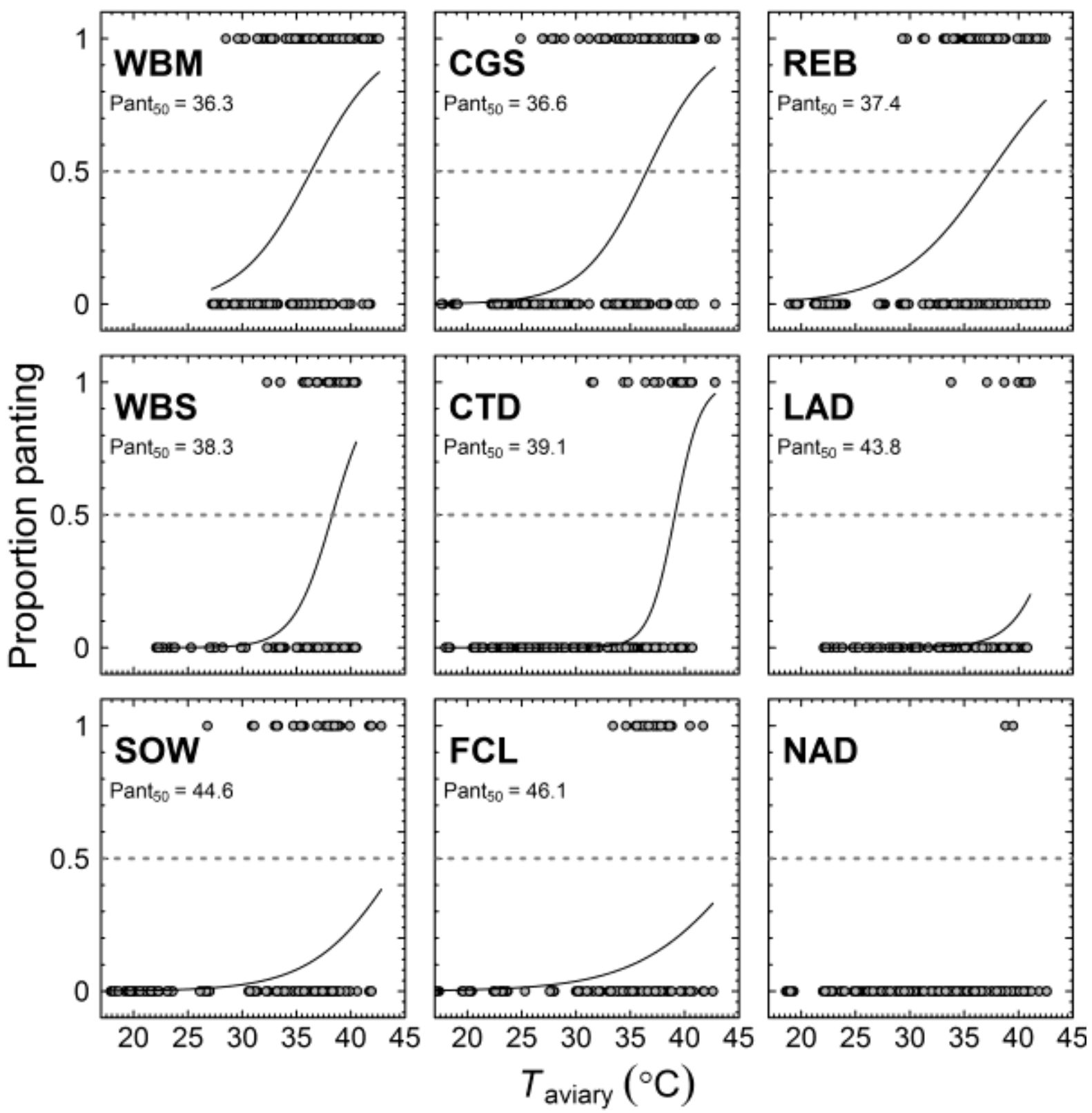

Figure 5: Proportion of time spent heat dissipating with increases in $T_{\text {aviary. }}$ Pant 50 is calculated as the $T_{\text {aviary }}$ at which $50 \%$ of observed individuals are displaying panting/gular fluttering. Gular fluttering observations in NAD were insufficient to calculate a significant pant 50 . WBM $=$ White-backed Mousebird, $C G S=$ Cape Glossy, REB = African Red-eyed Bulbul, WBS = White-browed Sparrow-Weaver, CTD = Cape Turtle-Dove, $\mathrm{LAD}=$ Laughing Dove, SOW $=$ Sociable Weaver, $\mathrm{FCL}=$ Fawn-coloured Lark, NAD = Namaqua Dove.

between panting and $T_{\text {aviary }}$ for this species (Figure 5). Moreover, neither $T_{\text {bmod }}$ nor mass correlated significantly with pant50. Shade-seeking behaviour was strongly temperaturedependent in all species excepting CTD and LAD, which were mostly confined to shady microsites in aviaries regardless of $T_{\text {aviary. }}$. However, the inflection points and slopes of the binomial regressions varied widely between species (Figure 6). 

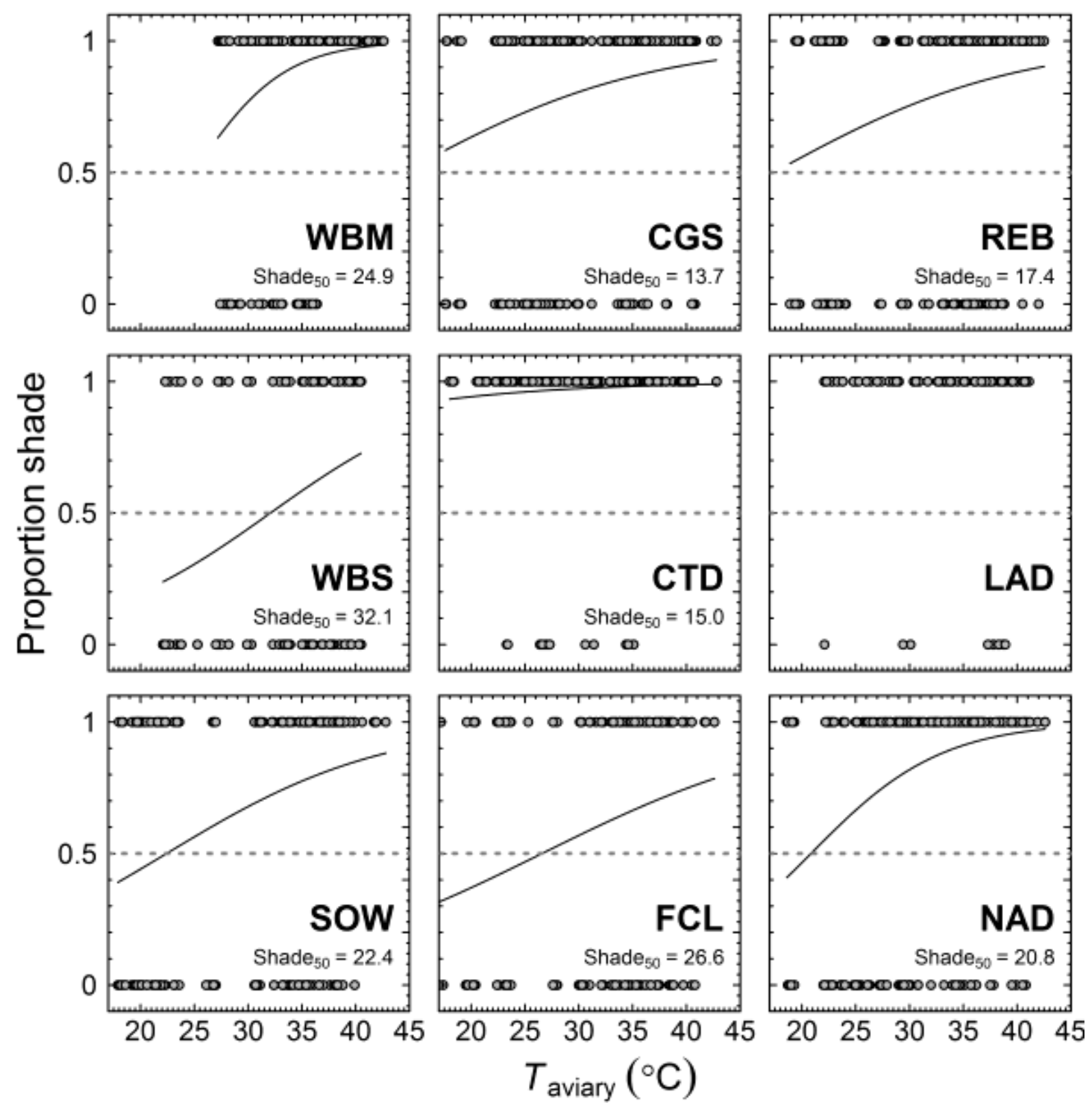

Figure 6: Proportion of time spent in the shade with increases in $T_{\text {aviary, }}$ where observations of birds in $1=$ dappled or full shade and $0=$ sun. Shade use increase with $T_{\text {aviary }}$ in all species except CTD and LAD, which spent most of the time in the shade. WBM = White-backed Mousebird, CGS = Cape Glossy, REB = African Red-eyed Bulbul, WBS = White-browed Sparrow-Weaver, CTD = Cape Turtle-Dove, LAD = Laughing Dove, SOW $=$ Sociable Weaver, $\mathrm{FCL}=$ Fawn-coloured Lark, NAD = Namaqua Dove.

\section{Discussion}

Our results reveal that arid-zone birds held under semi-natural conditions show considerable interspecific variation in $T_{b}$ patterns at high $T_{\text {air, }}$ with small but significant increases in $T_{\mathrm{b}}$ with $T_{\mathrm{air}}$ in most species, but some showing the opposite pattern. In addition, although shade-seeking and panting behaviour increased with $T_{\text {air }}$ in almost all 
species, the slopes were variable. Our data suggest patterns of thermoregulation that are strongly species-specific, with each species modulating behavioural and physiological aspects of thermoregulation differently.

Our study species generally had higher $T_{\text {bmod }}$ than typical avian active $T_{\text {bmean }}$ values (Prinzinger et al. 1991, Figure 1). Passerines in general appear to have slightly higher $T_{\text {bmod }}$ than columbids $\left(42.6 \pm 0.6^{\circ} \mathrm{C}\right.$ and $42.0 \pm 0.6^{\circ} \mathrm{C}$, respectively), also consistent with the conclusions of Prinzinger et al. (1991). One potential functional basis for the higher $T_{\text {bmod }}$ of passerines may concern their basal metabolic rates being $12 \%$ higher than those of non-passerine orders (Londoño et al. 2015). Of the nine species we investigated, freeranging $T_{b}$ patterns during hot weather have been examined previously in only WBS (Smit et al. 2013), work demonstrating that $T_{\mathrm{b}}$ patterns may vary both within and between populations under changing environmental conditions. In the present study, WBS showed higher summer $T_{\text {bmod }}\left(42.0 \pm 0.4^{\circ} \mathrm{C}\right)$ than previously recorded in free-ranging desert $(41.5 \pm$ $0.2^{\circ} \mathrm{C}$ ) and semi-desert $\left(40.2 \pm 0.3^{\circ} \mathrm{C}\right)$ populations (Smit et al. 2013) despite our study population being only $\sim 60 \mathrm{~km}$ west from the desert population studied by the latter authors. The higher $T_{\text {bmod }}$ value for WBS in the present study could reflect inter-population variation in $T_{\text {bset; }}$ but an alternative explanation is that in our study, captive conditions resulted in stress-induced hyperthermia [SIH; elevated $T_{b}$ in response to stress (Bakken et al. 1999, Carere et al. 2001, Keeney et al. 2001)] compared to free-ranging populations. Particularly for species that naturally exist solitarily or in pairs, captivity may encourage more frequent SIH due to stressful forced interactions (Cunningham et al. 2017). This may explain the higher $T_{\text {bmod }}$ in several of our species, not only WBS. Regardless, our $T_{\text {bmod }}$ data are still more likely to reflect $T_{\text {bset }}$ values of free-ranging birds as they are calculated from continuous $T_{\mathrm{b}}$ records from birds experiencing natural fluctuations in $T_{\text {air, }}$ whereas most previous $T_{b}$ data were collected during laboratory studies. 
Across our sample of species, thermoregulatory patterns appear to be speciesspecific. In most species, there were small but significant increases in $T_{b}$ with increasing $T_{\text {air, }}$ but in three species $T_{\mathrm{b}}$ decreased. In most species, $T_{\mathrm{b}}$ responses to increasing $T_{\text {air }}$ were also dependent on time of day, but the direction varied among species. This variability, together with the observation that in some species, $T_{b}$ showed no obvious response to increasing $T_{\text {air }}$ (e.g. FCL) whereas in others $T_{b}$ decreased with increasing $T_{\text {air }}$ (e.g. LAD) during the hottest part of the day, leads to several non-mutually exclusive explanations for the large interspecific variation in observed responses.

First, most species did not make prolonged use of facultative hyperthermia (defined here as $T_{\mathrm{b}}$ exceeding $T_{\mathrm{b} m o d}$ by $2^{\circ} \mathrm{C}$ or more) over the range of $T_{\text {air }}$ experienced during this study (Figure 7, Appendix). Increasing $T_{\mathrm{b}}$ with $T_{\text {air }}$ is a common physiological response in birds, thought to reduce evaporative water loss at high $T_{\text {air }}$ (Tieleman \& Williams 1999). Some species, e.g. SOW, CGS and WBS, did show small increases in $T_{b}$ above $T_{b m o d}$, but only NAD made use of facultative hyperthermia in the afternoons. The high afternoon $T_{b}$ of NAD illustrates the importance of time of day as a predictor of hyperthermia, as in most species there was little overall response in $T_{\mathrm{b}}$ to increasing $T_{\text {air }}$ (Figure 7 , Appendix). The more frequent hyperthermia in NAD is the pattern expected for a species closer to the generalist end of the thermal specialist/generalist continuum, where deviations in $T_{\mathrm{b}}$ from $T_{\text {bset }}$ are thought to have fewer negative effects on performance. However, this is confounded by hyperthermia shown in NAD being restricted to lower afternoon $T_{\text {air, }}$ suggesting an avoidance of high $T_{b}$ during the hottest times when hyperthermia would, theoretically, be most beneficial.

Tolerance of $T_{\mathrm{b}}$ values well above $T_{\mathrm{bmod}}$ also does not appear to be restricted to species with low $T_{\text {bmod. }}$ For example, of the two species with the lowest $T_{\text {bmod }}$ values in this study, WBM avoided hyperthermia, but NAD showed facultative hyperthermia during the afternoons. Species in which $T_{b}$ exceeded $T_{b m o d}$ also generally had higher $\mathrm{HI}$, but 
again NAD was the only species to show significantly higher variation in $T_{b}$ compared to other species. However, the distinct lack of response in $\mathrm{HI}$ to increasing $T_{\text {air }}$ in most species suggests that the range of $T_{\text {airs }}$ experienced in this study, or the free availability of water (see below), did not require the species we examined to allow a large variation of $T_{\mathrm{b}}$, complicating the process of evaluating links between hyperthermia use and shifts in thermal performance breadth. Despite the small magnitude of effect sizes in $T_{b}$ patterns, these effects are still likely to be biologically meaningful at very high $T_{\text {air }}$ when $T_{\mathrm{b}}$ approaches lethal limits, affecting rates of biochemical reactions and enzymatic structure (Hochochka \& Somero 2002, Angilletta et al. 2010). The overall variation in $T_{b}$ patterns between species highlights how complex and poorly understood is the ecological significance of avian facultative hyperthermia.

A second potential explanation for the large interspecific variation in observed responses is that behavioural adjustments accompanying changes in $T_{\mathrm{b}}$ with increasing $T_{\text {air }}$ were also variable, and species differed in their combinations of hyperthermia tolerance and behavioural changes in activity, panting and shade-seeking associated with thermoregulation. At high $T_{\text {air }}$ all species sought out shady microsites in the aviaries, however $T_{\text {air }}$ values at which shade-seeking took place varied widely (shadeso range: 13.7 $-32.1^{\circ} \mathrm{C}$ ) and were clearly species-specific (Figure 7). Similarly, activity patterns between species differed (activity50 range: $\left.8.2-48.9^{\circ} \mathrm{C}\right)$. Three species (WBM, CGS and SOW) reduced activity with increasing $T_{\text {air, }}$ but most species showed no change in activity levels. Generally, shade-seeking and reductions in activity buffer against physiological costs associated with evaporative cooling and hyperthermia by reducing exposure to higher heat loads (Dawson 1954, Wolf 2000, Angilletta et al. 2010; Boyles et al. 2011a). During hot weather birds either reduce foraging effort, limiting activity to the shade to avoid lethal hyperthermia, or continue foraging and thereby increase exposure to lethal hyperthermia and dehydration (Williams et al. 1999, Cunningham et al. 2015). We might therefore 
expect hyperthermia-avoiding species to adjust behaviour to a greater extent at high $T_{\text {air. }}$ While this may be true for some species, (i.e. WBM), it is clearly not the case for all. For example, LAD avoided hyperthermia, despite increasing activity with increasing $T_{\text {air }}$ and only initiating panting at $T_{\text {airS }}>37^{\circ} \mathrm{C}$ (Figure 6). One possible explanation for the ability of LAD to maintain $T_{\mathrm{b}}$ around $T_{\mathrm{bmod}}$ at high $T_{\text {air }}$ concerns the mechanism of evaporative cooling. Previous studies suggest that predominance of CEWL may provide a more efficient physiological basis to maintain $T_{\mathrm{b}}$ below $T_{\text {air, }}$ compared to taxa relying on panting (e.g. passerines) to dissipate heat (Marder \& Arieli 1988, McKechnie \& Wolf 2004). For example, under laboratory conditions columbids show more gradual increases in $T_{\mathrm{b}}$ at high $T_{\text {air }}$ (McKechnie et al. 2016) than passerines (Whitfield et al. 2015). In our study, the lower $T_{\text {bmod }}$ during hot weather of the two smaller dove species may reflect the greater efficiency of CEWL compared to panting in the passerines, as more efficient evaporative cooling pathways may result in lower $T_{b s}$ in general. The lack of reduction in activity with $T_{\text {air }}$ in most species is, however, supported by previous observations in the Kalahari, where few species have been shown to reduce activity significantly at high $T_{\text {air }} 39^{\circ} \mathrm{C}$ compared to milder $T_{\text {air }}$ of $29^{\circ} \mathrm{C}$, with most species reducing activity by only $10-20 \%$ at high $T_{\text {air }}$ (Smit 2013).

Finally, freely available drinking water during the course of the study may have ameliorated physiological trade-offs between increasing evaporative cooling to maintain $T_{b}$ below lethal limits and avoiding dehydration by conserving water (Dawson 1954), thereby creating a situation where $T_{\mathrm{b}}$ was regulated more precisely than it might have been in freeranging conspecifics. The ad libitum water supply may partially explain the negative or absent $T_{\mathrm{b}}$ response to increasing $T_{\text {air }}$ in some species and only small increases in $T_{\mathrm{b}}$ with $T_{\text {air }}$ in the remaining species (Table 3). During the present study, water and food was easily accessible and the energy needed to acquire it presumably a fraction of that under natural conditions for free-ranging birds. Consequently, birds may have drunk more 
frequently, permitting more evaporative cooling to take place compared to conditions with higher dehydration risk. This notion is supported by the observation that even species generally relying on preformed water as their main water source were regularly observed drinking water in the aviaries (WBM, WBS, SOW and FCL). Therefore, we argue that the provision of ad libitum water likely relaxed the dehydration-thermoregulation trade-off usually faced by free-living arid zone birds. Importantly, this easy access to water also explains the general lack of hyperthermia despite $T_{\text {air }}>40^{\circ} \mathrm{C}$. We were thus unable to identify any links between pant 50 and the use of hyperthermia. Species with high pant50 did not necessarily show high $T_{\text {bmod }}$ or an aversion for tolerating hyperthermia compared to species with low pant50. Smit et al 2016 suggested that larger birds, which have significantly lower pant50, should make more extensive use of evaporative cooling to avoid hyperthermia. However, freely available water may have influenced the relative use of evaporative cooling among species in this study, such that the relationship between pant50 and body mass was absent. Overall this suggests that, across the $T_{\text {air }}$ range investigated here, pant50 may not be a good indicator of physiological heat stress.

In conclusion, the variation in $T_{\text {bset }}$ among our study species and the difficulty in drawing any general patterns from behavioural and physiological responses to increasing $T_{\text {air }}$ emphasises the need for species-specific studies to understand a species' $T_{b}$ regulation. Many factors influence regulation of $T_{\mathrm{b}}$ in free-living birds, including factors we were not able to consider in this study. For example, recent research indicates that social status influences $T_{b}$ patterns, with dominant birds regulating more stable $T_{b}$ than subordinate individuals as $T_{\text {air }}$ increases (Cunningham et al. 2017). Additionally, the freely available water and food resources birds had access to during this study greatly underestimate the challenges free-ranging desert birds face in terms of balancing water and energy. As such, despite our attempts to make captive conditions as natural as possible, thermoregulatory patterns are likely to vary to an even greater extent 
intraspecifically between captive and wild populations. Further, interspecific thermoregulatory patterns will likely also vary more as unequal foraging-dehydration tradeoffs persist among wild species due to variation in their dependency on free-standing water and/or preformed dietary water.

Despite the difficulties of extrapolating data from captive birds to free-ranging individuals, captive studies do offer certain benefits including the opportunity for close and continuous behavioural and physiological observations and the practicability to experimentally manipulate resource availability. Little is currently known about how avian thermoregulation is adjusted when water availability is reduced. Captive studies may be the only way to effectively investigate and answer questions such as these and therefore are key to evaluating the usefulness of HDB thresholds to assess species vulnerability to increasing $T_{\text {air, }}$ and to further understand the complexities of thermoregulation in hot, arid environments.

\section{Acknowledgments}

We thank the Rossouw family for allowing us to conduct research on their property. We also thank the many field assistants for their valuable help in the field, and two anonymous reviewers whose comments greatly improved the manuscript. This study was approved by the University of Pretoria Animal Ethics Committee (project EC010-15) and complies with current South African laws. This study was supported by the National Science Foundation PEER Grant no. PGA-2000003431 to A.E.M. Additional funding was provided by the DSTNRF Centre of Excellence at the Percy FitzPatrick Institute at the University of Cape Town and University of Pretoria. This work is also based on research supported in part by the National Research Foundation of South Africa (Grant Number 110506). The opinions, findings and conclusions are those of the authors alone, and the National Research Foundation accepts no liability whatsoever in this regard. 
Declaration of interests: None

\section{References}

Altmann J. 1974. Observational Study of Behavior: sampling methods. Behaviour 49(3/4): 227-267.

Angilletta MJ, Cooper BS, Schuler MS \& Boyles JG. 2010. The evolution of thermal physiology in endotherms. Frontiers in Bioscience E2: 861-881.

Bakken M, Moe RO, Smith AJ \& Selle G-ME. 1999. Effects of environmental stressors on deep body temperature and activity levels in silver fox vixens (Vulpes vulpes). Applied Animal Behaviour Science 64(2): 141-151.

Bartholomew GA \& Cade TJ. 1956. Water consumption of house finches. Condor 58: $406-412$.

Barton K. 2010. MuMIn: Multi-model inference. R package version 0.13.17. http://cran.rproject.org/web/packages/MuMln.

Bates D, Maechler M, Bolker B \& Walker S. 2015. Fitting Linear Mixed-Effects Models Using Ime4. Journal of Statistical Software 67(1): 1-48. doi:10.18637/jss.v067.i01.

Boyles JG, Seebacher F, Smit B \& McKechnie AE. 2011a. Adaptive thermoregulation in endotherms may alter responses to climate change. Integrative and Comparative Biology 51:676-690.

Boyles JG, Smit B \& A. E. McKechnie. 2011b. A new comparative metric for estimating heterothermy in endotherms. Physiological and Biochemical Zoology 84:115-123.

Calder WA \& King JR. 1974. Thermal and caloric relations of birds. In: Ariun Biologic. Vol. IV (eds. DS Farner \& JR King), pp. 259-413. New York: Academic Press. 
Carere C, Welink D, Drent PJ, Koolhaas JM \& Groothuis TGG. 2001. Effect of social defeat in a territorial bird (Parus major) selected for different coping styles. Physiology \& Behaviour 73:427-433.

Cunningham SJ, Martin RO, Hojem CL \& Hockey PAR. 2013.Temperatures in excess of critical thresholds threaten nestling growth and survival in a rapidly warming arid savanna: a study of common fiscals. PLoS One 8(9):e74613.

Cunningham SJ, Martin RO \& Hockey PAR. 2015. Can behaviour buffer the impacts of climate change on an arid-zone bird? Ostrich 86(1-2):119-26.

Cunningham SJ, Thompson ML \& McKechnie AE. 2017. It's cool to be dominant: social status alters short-term risks of heat stress. Journal of Experimental Biology 220: 1558-1562.

Dawson WR. 1954. Temperature regulation and water requirements of the brown and Abert towhees, Pipilo fuscus and Pipilo aberti. In: University of California Publications in Zoology, (eds. GA Bartholomew, F Crescitelli, TH Bullock, WH Furgason \& AM Schechtman), pp. 81-123. Berkeley: University of California Press.

Dawson WR. 1982. Evaporative losses of water by birds. Comparative Biochemistry and Physiology 71(4): 495-509.

Dawson WR \& Bartholomew GA. 1968. Temperature regulation and water economy of desert birds. In: Desert biology, (ed. G. W. Brown), pp. 357-394. New York: Academic Press.

Dawson WR \& Schmidt-Nielsen K. 1964. Terrestrial animals in dry heat: desert birds. In Handbook of physiology: adaptation to the environment (ed. D. B. Dill), pp. 481-492. Washington, D.C: American Physiological Society.

Du Plessis KL, Martin RO, Hockey PAR, Cunningham SJ \& Ridley AR. 2012. The costs of keeping cool in a warming world: implications of high temperatures for foraging, 
thermoregulation and body condition of an arid-zone bird. Global Change Biology 18:3063-70.

Hochochka PW \& Somero GN. 2002. Biochemical Adaptation. Oxford University Press, Oxford.

Hothorn T, Bretz F \& Westfall P. 2008. Simultaneous Inference in General Parametric Models. Biometrical Journal 50(3): 346-363.IPCC. 2014. Climate change 2014: Synthesis Report. Contribution of Working groups I, II and III to the fifth assessment report of the Intergovernmental Panel on Climate Change [Core writing team, RK Pachauri and LA Meyer (eds.)]. IPCC, Geneva, Switzerland, 151 pp.

Keeney AJ, Hogg S. \& Marsden CA. 2001. Alterations in core body temperature, locomotor activity, and corticosterone following acute and repeated social defeat of male NMRI mice. Physiology \& Behaviour 74:177-184.

\section{Londoño G, Chappell M, Castañeda M, Jankowski J, Robinson S, \& Grémillet D.}

2015. Basal metabolism in tropical birds: Latitude, altitude, and the 'pace of life'. Functional Ecology 29(3):338-346. doi:10.1111/1365-2435.12348.

Marder J. \& Arieli U. 1988. Heat balance of acclimated pigeons (Columba livia) exposed to temperatures up to $60^{\circ} \mathrm{C}$ Ta. Comparative Biochemistry and Physiology Part $A$ 91:165-170.

McKechnie AE \& Wolf BO. 2004. Partitioning of evaporative water loss in white-winged doves: plasticity in response to short-term thermal acclimation. Journal of Experimental Biology 207:203-210.

\section{McKechnie AE, Whitfield MC, Smit B, Gerson AR, Smith EK, Talbot WA, McWhorter}

TJ \& Wolf BO. 2016. Avian thermoregulation in the heat: efficient evaporative cooling allows for extreme heat tolerance in four southern Hemisphere columbids. Journal of Experimental Biology 219:2145-55. 
Møller AP. 2010. Body temperature and fever in a free-living bird. Comparative Biochemistry and Physiology Part B 156:68-74.

Muggeo VMR. 2008. Segmented: an R package to fit regression models with broken-line relationships. R news, 8/1, 20-25. URL http://cran.r-project.org/doc/Rnews/.

Nilsson J, Molokwu MG \& Olsson O. 2016. Body temperature regulation in hot environments. PLoS One 11(8): e0161481. doi:10.1371/journal.pone.0161481.

O'Connor RS, Brigham RM \& McKechnie AE. 2017. Diurnal body temperature patterns in free-ranging populations of two southern African arid-zone nightjars. Journal of Avian Biology doi: 10.1111/jav.01341.

Prinzinger R, Preßmar A \& Schleucher E. 1991. Body temperature in birds. Comparative Biochemistry and Physiology 99A:499-506.

R Development Core Team. 2017. R: A language and environment for statistical computing. R Foundation for Statistical Computing, Vienna, Austria.

Hockey PAR, Dean WRJ \& Ryan P. 2005. Roberts' birds of southern Africa. 7th ed. Trustees of the J. Voelcker Bird Book Fund. Cape Town, South Africa.

Smit B. 2013. Taking the heat: integrating behavioural and physiological variables to predict avian responses to climate change in the Kalahari Desert. $P h D$ thesis. University of Pretoria. Pretoria, South Africa.

Smit B, Harding CT, Hockey PAR \& McKechnie AE. 2013. Adaptive thermoregulation during summer in two populations of an arid-zone passerine. Ecology 94(5):1142-54.

Smit B, Zietsman G, Martin RO, Cunningham SJ, McKechnie AE \& Hockey PAR. 2016. Behavioural responses to heat in desert birds: implications for predicting vulnerability to climate warming. Climate Change Responses 3:9.

Smith EK, O'Neill J, Gerson AR \& Wolf BO. 2015. Avian thermoregulation in the heat: resting metabolism, evaporative cooling and heat tolerance in Sonoran Desert doves and quail. Journal of Experimental Biology 218(22):3636-46. 
Tieleman BI \& Williams JB. 1999. The role of hyperthermia in the water economy of desert birds. Physiological and Biochemical Zoology 72:87-100.

van de Ven MFN. 2017. Implications of climate change on the reproductive success of the Southern Yellow-billed Hornbill, Tockus leucomelas. PhD Thesis. University of Cape Town. Cape Town, South Africa.

Whitfield MC, Smit B, McKechnie AE \& Wolf BO. 2015. Avian thermoregulation in the heat: scaling of heat tolerance and evaporative cooling capacity in three southern African arid-zone passerines. Journal of Experimental Biology 218:1705-14.

Williams JB, Tieleman BI \& Shobrak M. 1999. Lizard burrows provide thermal refugia for larks in the Arabian Desert. Condor 101: 714-717.

Williams JB, Tieleman BI \& Shobrak M. 2009. Validation of temperature sensitive radio transmitters for measurement of body temperature in small animals. Ardea 97: 120124.

Wolf BO. 2000. Global warming and avian occupancy of hot deserts: a physiological and behavioral perspective. Revista Chilena de Historia Natural 73: 395-400.

Wolf BO \& Walsberg GE. 1996. Thermal effects of radiation and wind on a small bird and implications for microsite selection. Ecology 77(7):2228-36. 


\section{Appendix}

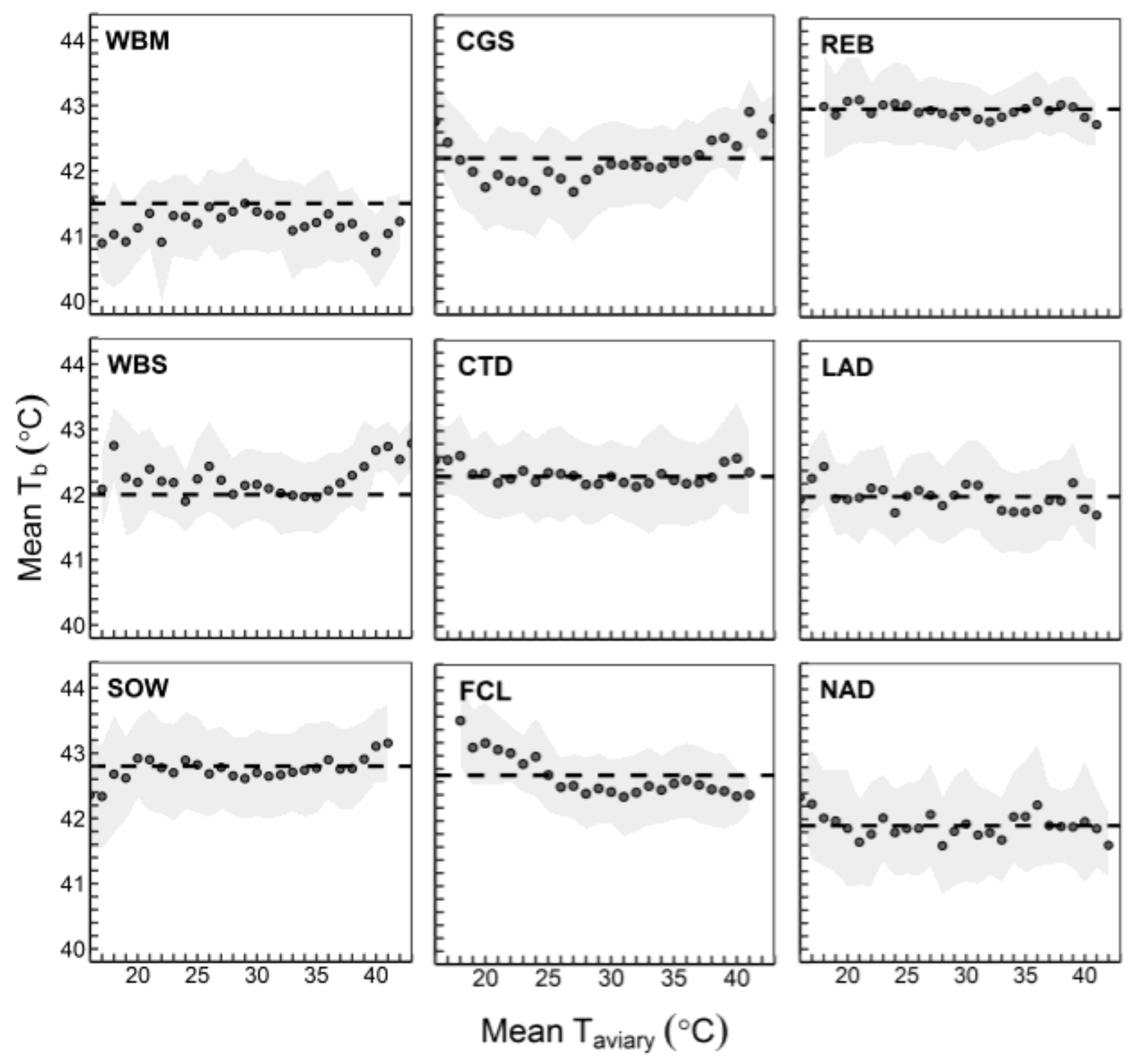

Figure 7: Mean increases in $T_{b}$ per degree $\left({ }^{\circ} \mathrm{C}\right)$ increase in $T_{\text {aviary }}$ for each species observed. White-backed Mousebirds (WBM), Laughing Doves (LAD) and Fawn-coloured Larks (FCL) decreased $T_{\mathrm{b}}$ with increasing Taviary whilst Cape Glossy Starling (CGS), White-browed Sparrow-Weaver (WBS), Cape Turtle-Dove (CTD), Sociable Weaver (SOW) and Namaqua Dove (NAD) increased $T_{b}$ with increasing $T_{\text {aviary. African Red-eyed }}$ Bulbul (REB) did not adjust $T_{b}$ with increasing $T_{\text {aviary. }}$ Grey ribbons represent standard deviation while dashed lines represent species $T_{\text {bmod. }}$. 


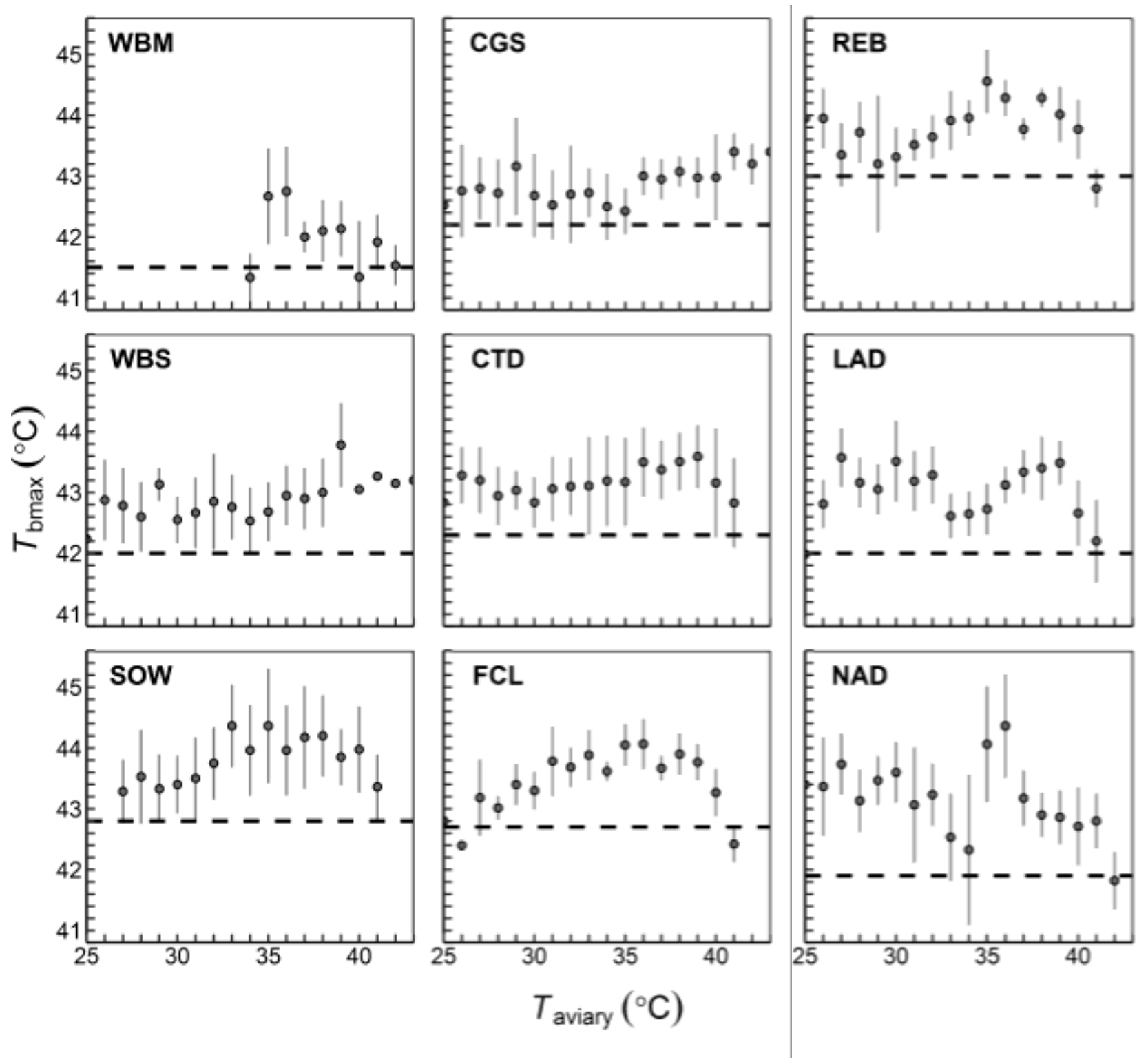

Figure 8: Mean increases in $T_{\text {bmax }}$ per degree $\left({ }^{\circ} \mathrm{C}\right)$ increase in $T_{\text {aviary }}$ for each species observed. Error bars represent standard deviation while dashed lines represent species $T_{\text {bmod. }}$ WBM $=$ White-backed Mousebird, CGS = Cape Glossy Starling, REB = African Red-eyed Bulbul, WBS = White-browed Sparrow-Weaver, CTD $=$ Cape Turtle-Dove, LAD = Laughing Dove, SOW $=$ Sociable Weaver, FCL $=$ Fawn-coloured Lark, NAD = Namaqua Dove. 